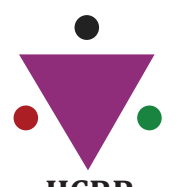

IJCRR

Section: Healthcare Sci. Journal Impact Factor: 6.1 (2018) ICV: 90.90 (2018)

\title{
Estimation of Reference Interval of Serum Progesterone During Three Trimesters of Normal Pregnancy in a Tertiary Care Hospital of Kolkata
}

\section{Arpita Mandal ${ }^{1}$, Sanchayan Sinha ${ }^{2}$, Soma Gupta ${ }^{3}$, Sanghamitra Chakraborty ${ }^{4}$}

\begin{abstract}
'Senior resident in Department of Biochemistry, Vidyasagar State General Hospital, Kolkata, West Bengal; ${ }^{2}$ Specialist Medical Officer in Basirhat General Hospital, West Bengal; 3Professor \& Head of Department of Biochemistry, NRS Medical College, Kolkata, West Bengal; ${ }^{4}$ Assistant Professor, Department of Biochemistry, NRS Medical College,Kolkata, West Bengal.
\end{abstract}

\section{ABSTRACT}

Aim: Hormonal milieu of pregnancy may be an important determinant of outcome in both mother \& fetus. Estimation of trimester specific hormone concentrations measured may serve as a yard stick to predict feto-maternal outcome. However, the literature review suggest that the reference interval of progesterone established in western pregnant population may not be applicable in India with different reproductive profile. The primary objective of this study was to estimate trimester specific and assay-specific reference interval of progesterone in healthy pregnant females.

Methodology: About 276 healthy pregnant ladies were enrolled as study participants with a distribution of 81 , 111, and 84 in 1 st $2^{\text {nd }} \& 3^{\text {rd }}$ trimester respectively. The study was conducted after obtaining ethical approval of Nil Ratan Sircar Medical College \& subjects were collected using pre-defined inclusion and exclusion criteria. Serum of study subjects was analysed for progesterone by Enzyme linked immunesorbent assay.

Results: The serum progesterone level was found to increase gradually throughout pregnancy.

Conclusion: The study helped us to determine the reference interval in healthy pregnant female and the reference values markedly differ from the established reference interval in other population.

Key Words: Progesterone, Reference values, Pregnancy Trimester

\section{INTRODUCTION}

Human reproductive endocrine function is intricately balanced by a wide variety of hormones \& their control by feedback mechanism. The menstrual cycle follows a cyclical deviation of luteinizing hormone (LH), follicle-stimulating hormone(FSH), estradiol, and progesterone orchestrated by hypothalmic-pituitary-gonadal axis ${ }^{1,2}$. The pregnancy is also maintained an intricate regulation of placental hormones and the hormonal milieu changes with duration of pregnancy. Thus, accurate assessment of the pregnancy duration is essential to predict the feto-maternal outcome. The endo- crinological changes of pregnancy is a crucial determinant of subsequent development of chronic diseases both in the mother and the offspring ${ }^{3,4}$. Estimation of trimester specific hormone concentrations measured may serve as a yard stick to predict feto-maternal outcome. Hormones estimation in early pregnancy where fetal organogenesis takes place may be helpful to assess neuro-developmental anomalies of fetus vis-à-vis hormone concentrations during late pregnancy may be helpful to assess maternal risk of breast and ovarian malignancies ${ }^{5,6}$. Progesterone is produced by the corpus luteum and regulate initial stage of pregnancy and sustain pregnancy until the luteal-placental shift takes place by 11 weeks of

Corresponding Author:

Dr. Sanghamitra Chakraborty, Assistant Professor, Department of Biochemistry, NRS Medical College, Kolkata, West Bengal. Mobile: 8017755640; Email: drsanghamitra84@gmail.com

ISSN: 2231-2196 (Print)

Received: 02.03 .2020
ISSN: 0975-5241 (Online)

Revised: 05.04 .2020
Accepted: 19.04 .2020 
gestation. Thus hormone concentration in luteal phase may predict the chances of conception as well as outcome of viable pregnancy. Progesterone, C-21 steroid hormone, synthesized by ovarian granulosa cells. Progesterone promotes endometrial decidualisation and assist implantation of the blastocyst in the uterine cavity ${ }^{7}$. Progesterone retards uterine smooth muscle contraction and ameliorates immune responses involved in graft rejection ${ }^{7}$. Recent studies have suggested that First trimester progesterone concentration is the most powerful single predictor of pregnancy outcome in natural conceptions ${ }^{8}$. Thus, it is necessary to study the viability of pregnancy in women after natural conception without exogenous micronized progesterone support and its relationship with serum progesterone ${ }^{9,10}$. Since the hormonal environment during pregnancy is likely to be a predictive variable for outcome of both mother and offspring, it is important to have an understanding of the factors which can affect it. A reference interval of this hormone may help to delineate whether any deviation had occurred or not. Most of the data regarding this is obtained from western literature, where the age group of pregnancy varies a lot with respect to that of Indian population. In this instance, the reference interval of serum progesterone was established in the three trimesters of Pregnancy and evaluated to assess any deviation from western population.

\section{MATERIALS AND METHODS}

This study was undertaken in the Department of Biochemistry in collaboration with the Department of Obstetrics and Gynaecology, NRS Medical College and Hospital, Kolkata. The study was initiated after approval from Institutional Ethics Committee of NRS Medical College \& Hospital (vide memo no NMC/6534 dated 26/12/2016). All the voluntary participants were included in the study after signing the consent form. All healthy pregnant females having no history of pre-existing disease or any complication were included in this study. Pregnant females who had treatment for infertility, or found to have any other pregnancy associated co-morbidities were excluded in this study. The cases were selected from the pregnant females attending Antenatal clinics in the Department of Obstetrics and Gynaecology of N.R.S. Medical College \& Hospital, Kolkata, according to predefined inclusion and exclusion criteria. Proper history was taken regarding age, parity, detail history of previous pregnancy, history of hypertension, family history, history of taking any medicine, and history of whether suffering from any other medical disorders. About $4 \mathrm{ml}$ blood was collected from each patient aseptically by disposable syringe using aseptic procedure in serum separation tubes. The serum sample tubes was centrifuged for 5 minutes at 2500 . The serum was separated from the blood cells, analysed and was kept in aliquots and stored in deep freezer at $-40^{\circ} \mathrm{C}$.Serum of pregnant women collected in first trimester, second trimester and third trimester was analysed for progesterone by Enzyme linked Immunosorbant assay.

\section{RESULTS AND DATA ANALYSIS}

This hospital based study incorporated 276 pregnant ladies as study subjects. The trimester wise distribution of study population was 81,111 , and 84 study participants in $1^{\text {st }}, 2^{\text {nd }} \&$ $3^{\text {rd }}$ trimester respectively. The values of the hormones were extrapolated in Microsoft excel sheet and calculation was done using MedCalc software (version 18.9). Table 1 shows trimester specific reference interval of progesterone. The study participants were enrolled using pre-defined inclusion and exclusion criteria, after subsequent routine clinical and investigational procedure.

It is evident that the number of study participants were less than 120 i.e. as per the IFCC recommendations. So the nonparametric method was used to assess the reference interval. Moreover, the Kolmogorov-Smirnov test showed that the reference values were in non-Gaussian distribution (i.e $\mathrm{P}<0.05$ ). Thus a non-parametric approach was done to calculate the reference values.

Table 1: Reference Interval of Progesterone (ng/ml)

\begin{tabular}{lcccc} 
Trimester & $\begin{array}{c}\text { Lower } \\
\text { limit }\end{array}$ & $\begin{array}{c}\text { Confidence } \\
\text { interval } \\
(\mathbf{9 0} \%)\end{array}$ & $\begin{array}{c}\text { Upper } \\
\text { limit }\end{array}$ & $\begin{array}{c}\text { Confidence } \\
\text { interval } \\
(\mathbf{9 0} \%)\end{array}$ \\
First & 5.49 & $4.47-6.95$ & 93.09 & $73.13-119.06$ \\
Second & 6.57 & $5.22-8.61$ & 247.67 & $181.92-333.92$ \\
Third & 95.56 & $80.24-117.49$ & 908.87 & $745.06-1084.22$ \\
\hline
\end{tabular}

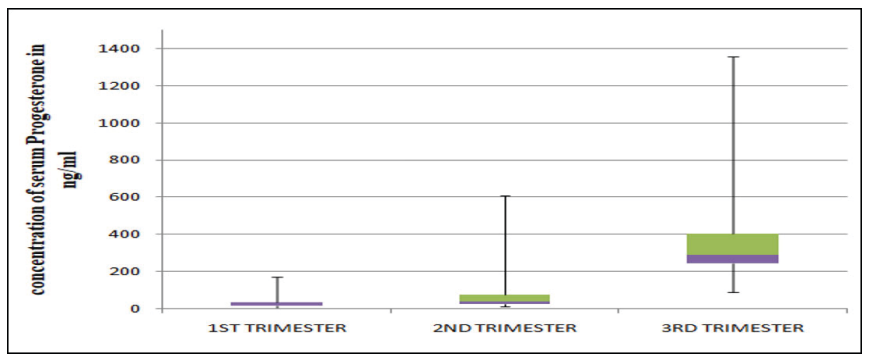

Figure 1: Showing reference values of progesterone of pregnant ladies in each trimester.

\section{DISCUSSION}

Hormones play an important role defining the optimal conditions for human inception. The corpus luteum, adrenal cortex and the maternal ovary are the main reservoir for synthesis of maternalestradiol, estrone, and progesterone during the first 9 weeks of gestation. Gradually, from the second trimester 
site of synthesis of the steroid hormone shifts to the placental trophoblast $\mathrm{t}^{11-13}$ and their concentrations continue to increase. In this study, the age distribution of study population is between 17 to 36 years. Among them, 51 were primigravida women and 225 were multigravida. The mean concentration of serum progesterone in first trimester was found 30.88ng/ $\mathrm{ml}$, in second trimester was found $75.63 \mathrm{ng} / \mathrm{ml}$, in third trimester was found $379.22 \mathrm{ng} / \mathrm{ml}$. This is in concordance with the established change of progesterone in healthy pregnant females. According to table 1, the reference interval of serum progesterone for first trimester based on robust method was $5.49-93.09 \mathrm{ng} / \mathrm{ml}$, for second trimester was $6.57-247.67 \mathrm{ng} /$ $\mathrm{ml}$, for third trimester was $95.56-908.87 \mathrm{ng} / \mathrm{ml}$. This provides here a useful image of the reference interval and distribution. A similar study was performed in the Laboratory of Clinical Chemistry at the Umeå University Hospital, Umeå, Sweden. The mean concentration was $25.2 \mathrm{ng} / \mathrm{mL}$ for progesterone during first trimester of pregnancy, which was similar to our study findings..$^{13}$ In the study of RT roisi et al for progesterone, the highest hormone concentrations were generally observed in nulliparous women less than age 30 years and the lowest concentrations in parous women age 30 years. In contrast, nulliparous women age $30+$ years had higher progesterone concentrations than younger nulliparous women or parous women of any age ( $\mathrm{P}$ for interaction $=0.006$ ). A study on maternal progesterone concentration by Schock et al showed a decrease in pregnancy progesterone levels in pregnancy with female offspring, where blood at 16 and 27 weeks ${ }^{14}$. However, due to strictures of PNDT act no such comparison could be made. Moreover, the admixture of both primigravida and multigravida was a constrain to our statistical analysis. However, the reference values was slightly higher than the established reference values in western literature.

\section{CONCLUSION}

This study was undertaken with the aim to establish trimester specific and assay-specific reference interval of progesterone in healthy pregnant female in a tertiary care hospital of Kolkata. No such study or data is so far available from Kolkata or North East region of India. Most of the data regarding this is obtained from western literature, where the age group of pregnancy varies a lot with respect to that of Indian population. Reference interval of serum progesterone for first trimester was 5.49 to $93.09 \mathrm{ng} / \mathrm{ml}$, for second trimester was 6.57 to $247.67 \mathrm{ng} / \mathrm{ml}$, for third trimester was 95.56 to $908.87 \mathrm{ng} / \mathrm{ml}$. Despite the limitations imposed by both primigravida and multigravida as samples, an approximation of reference values of Progesterone could be made. Moreover, analysis of other parameters like Ultrasonography findings and a comparative evaluation of fetal outcome may strengthen the study results and may be helpful to use the cut-off values of progesterone as predictive marker.

\section{ACKNOWLEDGEMENTS}

Authors acknowledge the immense help received from the scholars whose articles are cited and included in the references of the manuscript. The authors are also grateful to authors/editors. Publishers of all those articles, journals and books from where the literature for this article has been reviewed and discussed. All those who have significantly contributed in this study are included as author. All the authors sincerely pay gratitude to all the patients and healthy subjects who have given their blood for analysis and actively participated in the study.

Conflict of interest: There is no conflict of interest associated with this article.

Source of funding: There is no external funding agency associated with this article.

\section{REFERENCES}

1. Gronowski AN, Landau-Levine ME. Reproductive endocrine function. In: Burtis CA, Ashwood ER, editors. Tietz fundamentals of clinical chemistry. Philadelphia: WB Saunders, 2001:877-97.

2. Marshall JC. Hormonal regulation of the menstrual cycle and mechanisms of ovulation. In: DeGroot LJ, Jameson JL, editors. Endocrinology. Philadelphia, PA: WB Saunders, 2001:2073-85.

3. Lukanova A, Surcel HM, Lundin E, Kaasila M, Lakso HA, Schock H, et al.Circulatingestrogens and progesterone during primiparous pregnanciesand risk of maternal breast cancer. Int J Cancer. 2012;130(4):910-20.

4. Whitaker-Azmitia PM, Lobel M, Moyer A. Low maternal progesterone may contribute to both obstetrical complications and autism. Medical hypotheses. 2014;82(3):313-8.

5. Braem MG, Onland-Moret NC, Schouten LJ, Kruitwagen RF, Lukanova A, Allen NE, et al. Multiple miscarriages are associated with the risk of ovariancancer: results from the European Prospective Investigation into Cancer and Nutrition. PloS one. 2012;7(5), e37141.

6. Beral V, Bull D, Doll R, Peto R, Reeves G. Breast cancer and abortion: collaborative reanalysis of data from 53 epidemiological studies, including83 000 women with breast cancer from 16 countries. Lancet. 2004;363(9414):1007-16.

7. Hanita $\mathrm{O}$, Hanisah AH. Potential use of single measurement of serum progesterone in detecting early pregnancy failure. Malaysian J Pathol 2012; 34: 41-6.

8. Elson J, Salim R, Tailor A, Banerjee S, Zosmer N, JurkovicD. Predictionof early pregnancy viability in the absence of an ultrasonically detectable embryo. Ultrasound Obstet Gynecol 2003; 21: 57-61.

9. Vicdan K, ZekiIsik A. Luteal phase hormonal profile in prediction of pregnancy outcome after assisted reproduction. Eur J Obste Gynecol Reprod Biol 2001; 96: 98-101.

10. Zainab Ali Abdulla Al Jufairi. The value of Serum ProgesteroneMeasurement in Early Pregnancy. Bahrain Medical Bulletin, Volume22, Number 1, March 2000.

11. Hanita O, Hanisah AH. Potential use of single measurement of serum progesterone in detecting early pregnancy failure. Malaysian J Pathol 2012; 34: 41-6.

12. Elson J, Salim R, Tailor A, Banerjee S, Zosmer N, Jurkovic D. Prediction of early pregnancy viability in the absence of 
Mandal et.al: Estimation of reference interval of serum progesterone during three trimesters of normal pregnancy in a tertiary care hospital ...

an ultrasonically detectable embryo. Ultrasound ObstetGynecol 2003; 21: 57-61.

13. Vicdan K, ZekiIsik A. Luteal phase hormonal profile in prediction of pregnancy outcome after assisted reproduction. Eur J Obste Gynecol Reprod Biol 2001; 96: 98-101.
14. Wuu J, Hellerstein S, Lipworth L, Wide L, Xu B, Yu GP, et al. Correlates of pregnancy oestrogen, progesterone and sex hormone-binding globulin inthe USA and China. Eur J Cancer Prev. 2002;11(3):283-93. 